\title{
TEACHERS' BELIEFS OF THE IMPLEMENTATION OF COMMUNICATIVE LANGUAGE TEACHING AT PRIMARY SCHOOL LEVEL IN ZIMBABWE
}

\author{
Mildred Shingirirai Nyamayedenga, Women's University in Africa, Zimbabwe
} Lizette de Jager, University of Pretoria, South Africa

Communicative language teaching (CLT) is considered as a teaching approach that assists learners to achieve communicative competence. However, it seems as though a major gap exists regarding how teachers' beliefs affect the implementation of CLT in primary school. In the study reported on here, we examined how primary school teachers' beliefs affect the way in which CLT is implemented in Zimbabwe using a case study of five purposively selected teachers. The analysis aimed to explore what the teachers believed about CLT and how their beliefs were reflected in their classroom practices. The study adopted an inductive thematic analysis that permitted an understanding of how teacher beliefs affected classroom practice through teacher-learner and learner-learner interactions. Data from classroom observations, interviews, documents and field notes were analysed to reveal the phenomenon under study. A major finding of this study reveals that teachers hold beliefs that are not in support of the use of CLT. These beliefs are pedagogical and methodological, and both influence the way in which CLT is implemented. Teachers had their own ideas about CLT and the activities that should be used when implementing it. The teachers' beliefs were established through observing how teachers implemented CLT and through the knowledge that they had about the approach. In view of the foregoing major finding, it is recommended that teacher training colleges should not emphasise traditional methods of teaching but rather focus more on CLT as a teaching approach.

Keywords: Communicative competence, communicative language teaching, classroom practice, English as a second language, teachers' beliefs

\section{INTRODUCTION}

English is taught as a second language in most countries around the world (Kadenge \& Nkomo, 2011; Mutekwa, 2013), as is the case in Zimbabwe. Communicative language teaching (CLT) is used as an approach to teaching English as a second or foreign language in Asia and Africa (Rahman, Singh \& Pandian, 2018: 296). The importance of being competent in the global village has made English critical in teaching, learning and communication. One of the ways for learners to achieve communicative competence in English is using the CLT approach, hence its adoption by the Ministry of Primary and Secondary Education in Zimbabwe (Ministry of Education, Sport, and Culture, 1986).

In the Zimbabwean context, primary school education comprises nine years, a period that spans from early childhood development (ECD A and B) to grade 7. Formal learning begins at grade 1 level and continues up to higher education (Kanyongo, 2005: 67). In Zimbabwe, English is used as the medium of instruction from grade 3 to 7 at primary level in all the subjects, except in the teaching of local languages. However, primary school learners have problems in articulating themselves during oral and written work (Pretorius, 2014: 52). As a 
result, learners' communicative competence remains a challenge at both secondary and tertiary level as they carry on without the necessary skills that are supposed to be welldeveloped by the end of primary schooling. The purpose of this article is to report on a study that sought to explore teachers' beliefs and how they affect CLT implementation in five selected primary schools in Zimbabwe.

\section{BACKGROUND}

Research suggests that teaching methods that facilitate learners' active learning and creativity should be prioritised over those that promote passive and rote learning, which are the traditional methods of teaching (Drake, 2012: 38-40; Ginsburg, 2009: 6). CLT is an example of a teaching method that facilitates active learning and promotes and develops learners' ability to communicate using a language (Brown, 2014; Littlewood, 2014; Ounis \& Ounis, 2017). Mareva and Nyota (2012: 105) claim that CLT is helpful in assisting learners to interact using language in context. Thus, if implemented effectively, CLT yields good results in both spoken and written exercises for learners.

In our investigation, we assumed that failure to implement CLT effectively may be attributed to the beliefs held by teachers. This is supported by Nishino (2012: 380), Niu and Andrews (2012: 135) and Kim (2014: 75), who state that the way teachers implement CLT may be affected by the beliefs they hold. Niu and Andrews (2012: 135), in agreement, state that there is a clear correlation between teachers' beliefs and their classroom practices. In the study, we define beliefs as the understanding that teachers have about CLT, what they think about this approach and how it guides their teaching practices. Teachers do have their own beliefs, which mirror individual philosophies of teaching (Rahman, Singh \& Pandian 2018: 296). Although most studies have found that teachers' beliefs link with their practices, some studies have found that teachers' beliefs may not link with their classroom practices, in that what they believe in may not be implemented due to different factors like large class sizes and a lack of adequate resources (Rahman, Singh \& Pandian 2018: 296). In agreement with Xu (2012:1397), we note that teachers' beliefs may play a big role in their teaching and may influence the way they scheme and plan for their lessons. In a study by Nyawaranda (1998), Zimbabwean secondary school teachers' belief about the teaching of English as a second language were explored. Nyawaranda's (1998) study did not specifically address the beliefs held by teachers about CLT implementation at primary school. Given this background, the main argument put forward in this article is that teachers at primary school may have different beliefs, which may affect the way they implement CLT. It is therefore critical to understand the beliefs that primary school teachers hold in order to understand the way in which teachers implement CLT. Therefore, in our study, we aimed to explore teacher beliefs and how they affect the implementation of CLT.

\section{PROBLEM STATEMENT}

According to the 2014 grade 7 report of the Zimbabwe School Examination Council (the examining board), primary school learners perform poorly in English language. Learners of English at primary school level in Zimbabwe face challenges in acquiring communicative competence in the language. This is an indication that the learning and teaching of English at primary school may be fraught with problems. We assumed that, if teachers hold beliefs that are in support of CLT, they may implement CLT effectively to assist learners in becoming communicatively competent. We were also of the opinion that the beliefs held by teachers affect how CLT is implemented at primary school level. The aim of the research was to 
explore teachers' beliefs about CLT and how those beliefs affect CLT implementation. The research addresses a particular knowledge gap, as it would seem that few or no scholars in the Zimbabwean primary school context have investigated teachers' beliefs of CLT at primary school level.

The main research question guiding the study was: How do teachers' beliefs affect the implementation of CLT?

The main research question was supported by the following sub-research question: What do the activities used by teachers to implement CLT reveal about their beliefs?

\section{COMMUNICATIVE LANGUAGE TEACHING IN ZIMBABWE}

The Zimbabwean primary school syllabus for grades 1 to 7 (Ministry of Education, Sport, Arts and Culture, 1986) requires teachers to use CLT to assist learners to become communicatively competent in English. Littlewood (2013:3) defines CLT as an approach that may be used by teachers to improve learners' ability to communicate. Communicative language teaching can also be viewed as a learner-centred approach to language teaching (Ying, 2010). CLT stresses the development of communication, and learners interact among themselves while the teacher acts as guide to helps learners acquire language in the teachinglearning process (Brown, 2001; Richards \& Rodgers, 2001; Sekiziyivu \& Mugimu, 2017). In principle, CLT is an approach that encourages interaction and allows learners to use language meaningfully and in context. The main aim of CLT is to enhance learners' communicative competence in English (Littlewood, 2013:1). Findings by Nziramasanga (1999), who inquired into the state of education in Zimbabwe, support the primary school English syllabus and recommend the use of CLT to make the learning of English functional and purposeful. Ahmad and Rao (2013: 190) acknowledge that CLT as a communicative approach may be more effective than traditional language teaching methods like grammar translation and audiolingual language methods; CLT provides a basis for learner-centred and problemsolving activities. These definitions show that researchers who support CLT view it as an interactive method that helps learners to solve problems. They also interpret it as a broad idea about the nature of language learning and teaching, which is viewed differently by different scholars (Brown, 2007; Hiep, 2007; Littlewood, 2013). This means that CLT is considered as an approach rather than a method, and thus may be employed using different activities that increase communication. The Zimbabwean primary school syllabus suggests that role-play, pair and group work, dialogues, drama, and information gap activities should be used to motivate and sustain learners' interest during interaction. Asl (2015: 23), Parvin (2016: 399) and Richards (2006: 14) identify role-play and discussions as activities that provide learners with chances of interaction to improve their fluency. Pair and group work are used in CLT implementation to assist learners to discuss and support each other (Ounis \& Ounis, 2017: 191). Dialogues may be used by the teacher as an activity to help learners interact using language in real-life situations (Sari, 2014: 2). The syllabus suggests that CLT activities should be authentic and that primary school teachers in Zimbabwe should integrate different interactive methods for teaching and learning in a CLT classroom. Teachers should further take cognisance of the context within which they are operating in order to come up with a version of CLT that prioritises interaction. The CLT approach is suitably prescribed for implementation in the Zimbabwean primary school context. In this article, we argue that there may be a link between what teachers believe and what they do, hence the need for the study. 


\section{CONCEPTUAL FRAMEWORK}

The research was framed against the activity theory (Engeström, 1987, 2014), sociocultural theory (SCT) (Vygotsky, 1978) and experiential learning theory (ELT) (Kolb, 1984). We argued that the activity theory, ELT and SCT are all theories of CLT. The theories resonate with CLT because of the view that all learning activities should be meaningful and goaldirected. We explored the core concepts of SCT, which include scaffolding, the zone of proximal development, more knowledgeable other and mediation (Xiangui, 2005). These core concepts by Vygotsky (1978) maintain that higher psychological functions originate in interaction between individuals (inter-psychological level) before they are transferred within an individual (intra-psychological level) (Wertsch 1985: 166). These theories share the view that interaction between teacher and learners and among learners is one of the key elements that help to achieve communicative competence. SCT holds that language is a socially constructed phenomenon. Language may be learnt when learners are socialising with their peers (Brown \& Gaskins, 2010: 199; Luna Scott, 2015: 2). This implies that teachers should ensure that learners participate through engaging in activities, talk and collaborative work during English lessons (Vygotsky, 1978; Cross, 2010). This may be done if the teacher uses CLT activities that help learners to work together.

In ELT, learning is drawn from experience, which is followed by reflection (Kolb, 1984). According to ELT, teachers should reflect to determine whether the activities they use allow learners to interact with each other. In relation to Vygotsky's SCT, learners should be given an opportunity to interact among themselves. Similarly, in experiential learning the teacher should ascertain that learning has been scaffolded through classroom interaction in order for learners to reach their potential. In the CLT classroom, teachers should ensure that they develop the learners' target language skills (communicative competence) through interactive activities. This notion of interaction is supported by Fatemeh and Hamidreza (2012: 269), who state that experiential learning is established on the belief that learners should participate in and reflect on their learning. In ELT, learners may learn a language through the experience of working together on given tasks.

\section{RESEARCH DESIGN AND METHODOLOGY}

In this research we used a qualitative approach, influenced by the interpretivist constructivist paradigm and a single case study design. Data were collected through non-participatory observations, semi-structured interviews and document analysis. The observations were the main data collection instruments, while interviews and documents were used to verify what was happening in the classroom with what teachers said they were doing. In this way, teachers' beliefs were brought out clearly. All three instruments helped us to elicit data that assisted in understanding how the implementation of CLT was affected by teacher beliefs. For data analysis, we used inductive thematic analysis. Data were analysed inductively by identifying, analysing, organising, describing and reporting themes found within collected data (Nowell, Norris, White \& Moules, 2017: 2).

\section{Participants and sampling procedures}

Purposive sampling was used to select five teachers from five primary schools. The criteria used to select the participants were that they should hold a diploma in education from any teacher training college in Zimbabwe and that they taught grade 7 learners. The research was carried out in the Harare Metropolitan Province. For ethical considerations, trustworthiness, 
transparency and confidentiality, the names of the participants and their schools were not disclosed (Denzin \& Lincoln, 2005; Maree, 2007; Kaiser, 2009). The participants were given colour pseudonyms for anonymity purposes. The Ministry of Education Director, the district officer and head teachers of participants granted us written permission to conduct research in the schools. Teachers also gave their consent to be observed, interviewed and audiotaped.

\section{FINDINGS}

This research was based on the assumption that effective CLT implementation may be affected by the beliefs held by teachers. The main findings revealed that the way teachers implemented CLT (teacher's classroom practice) was informed by the methodological and pedagogical beliefs that they held. These beliefs were illuminated through observations, interviews, and document analysis. The observations assisted us in establishing the teachers' beliefs through the activities that they used in their classrooms, while the interviews shed light on the knowledge and understanding that teachers had regarding the CLT approach. The information gleaned from the documents did not agree with what the teachers said that they had done in the classrooms.

Figure 1 shows the themes emerging from the data collected through observation, interviews and document analysis. The sub-research question: 'What do the activities used by teachers to implement CLT reveal about their beliefs?' was answered under the theme of methodological beliefs.

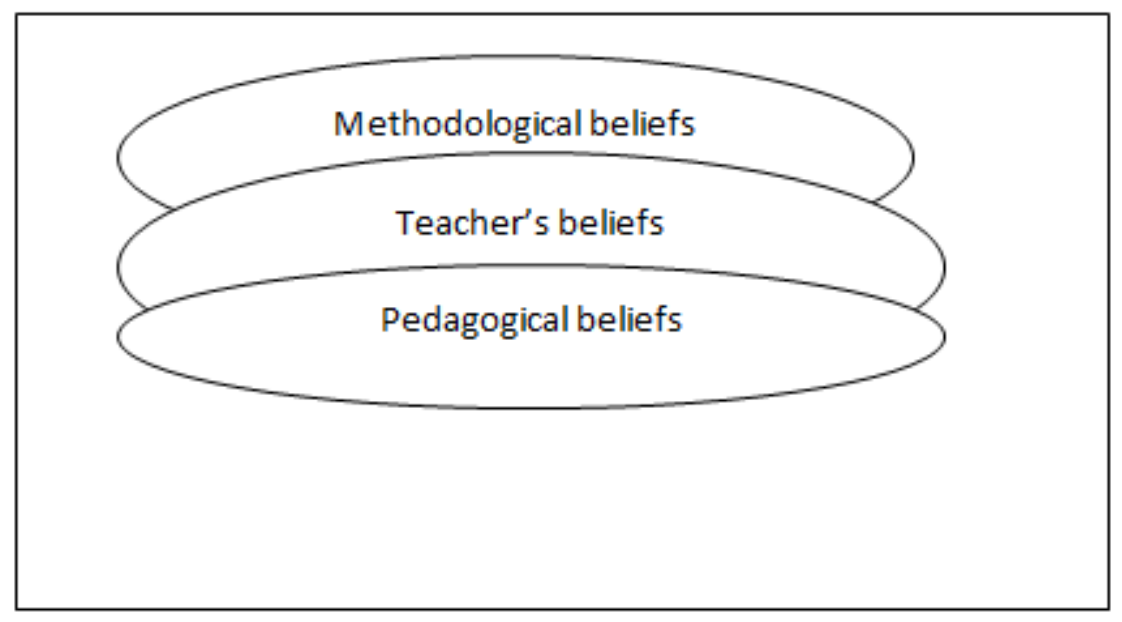

Figure 1: Themes for the study

\section{Participants' methodological beliefs}

Methodological beliefs held by teachers emerged through the activities that they used in the CLT classrooms. These methodological beliefs were a result of what teachers thought and knew were the best activities that they could use to achieve their lesson objectives. The findings from this study showed that teachers preferred using certain activities in the teaching of English. Group work was one of these. We observed that, during group work, two teachers divided the learners into groups of eight and the other three teachers used groups of ten. This did not positively impact individual performances because the groups were too large for communicative learning to take place. As a result, some learners did not participate but played around while one or two members in the group did the work. This finding agrees with Burke's 
(2011: 89) finding that large groups were ineffective as learners' chances of participation were reduced.

During the semi-structured interviews, participants Green, Pink and White confirmed that they avoided interactive activities, as these tended to prolong their lessons. All the participants agreed that the CLT approach worked well, if only they did not have to meet the demands of the Ministry of Education, which are two daily written exercises in English, one composition per week and two comprehension passages per week (Ministry of Education, Sport and Culture, 2006). Participant Green elucidated that the merits of interactive methods like group work surpassed its demerits, yet it was difficult to use the activity all the time due to time constraints. What this suggests is that teachers theorise the use of interactive activities, but do not use them in practice. This is in line with Taebi, Torabi and Farsani (2016: 47), who found that teachers struggled to apply theory in practice because of time constraints and the beliefs they held.

We observed that, when the participants used group work, their lessons did not end on time. For example, participant White's lesson lasted an hour instead of 30 minutes. We concluded that, although the use of pair and group work seemed to align the observed lessons to the philosophy of CLT, it was not used effectively. The use of group work was affected by the teachers' beliefs that it was time-consuming, although they believed that it was one of the interactive activities that they could easily use. Although group work was recorded in the participants' scheme-cum-plans (scheme-cum-plan is a school record of work showing what is to be done on a day-to-day basis for a school term) as it was required by the syllabus and viewed as an effective way of creating natural dialogue by the head teachers, these activities were implemented ineffectively.

During the observations, we established that participant Pink used an interactive activity, which was a dialogue as an activity in a lesson on prepositions, in which participant Pink requested the learners to develop a dialogue using the given prepositions. In this lesson, learners were required to be creative. The first pair showed a great deal of creativity during the dialogue, which could be an indication that they understood what the teacher required of them. However, the second pair of learners failed to practice a dialogue and participant Pink discarded the activity. Instead of assisting the learners, she asked them to look at the exercise on the board to do a different activity.

Moreover, we observed that teachers were not using interactive activities; instead, they used a great deal of drilling or rote learning. Learners were asked to repeat through chorusing to memorise what they were being taught. Once a learner gave a correct answer, the teacher would ask the whole class to repeat the answer. Participants conceded to the use of repetition as a way to assist learners to grasp what they were being taught. They believed that repetition assisted learners to commit to memory what they had been taught for examination purposes.

In addition, all observed lessons highlighted teacher-centred learning. Learners were restricted to answering questions and receiving commands from the teacher, which does not support the principle of CLT in which learners are required to create knowledge and negotiate meaning. The aforementioned showed that learners were not given an opportunity to engage in sustained interactions with the teacher and learners. The learners were not afforded opportunities to interact among themselves. Teachers asked simple questions which allowed learners to give factual answers. Teachers and learners did not engage in conversation in which the learners were allowed to interact. Once the teachers discovered that learners knew 
the answers, they were satisfied and did not require any additional information from the learners. We established that the way the teachers taught did not enable learners to interact effectively and develop the desired language skills, as proposed by Al-Zahrani and Al-Bargi (2017: 135).

We deduced that the participants employed more traditional methods of teaching as they were not conversant with the CLT approach. From participant Green's response, it was clear that she did not understand CLT: 'I think when you visit us, it's better for you to leave some handouts that will help us in the teaching of Communicative Language Teaching.'

We established that teachers corrected learner errors as soon as they were uttered. This was because of the teachers' methodological beliefs that it would be difficult to un-teach something once the learners had mastered the wrong things. This finding suggests that participants were using the audio-lingual method and grammar-translation method, which allow the teacher to correct errors as soon as they are made. Based on the observed lessons, one could deduce that the classroom activities were characterised by traditional methods of language teaching.

\section{Participants' pedagogical beliefs about communicative language teaching}

In this section, we comment on how teachers' views about CLT affected the implementation thereof. Important information on teachers' knowledge and understanding of CLT was revealed through their views on CLT. These views elucidated the participants' pedagogical beliefs about the CLT approach. Pedagogical beliefs relate to the way in which primary school teachers interpret CLT, which result in the way they implement CLT in lessons. Through the participants' knowledge of CLT, we were able to understand how their pedagogical beliefs affected or influenced the way CLT was implemented. The participants' inadequate knowledge of CLT was a cause for concern. This was evident as some of the participants believed that CLT was simply passing on information to learners, which was confirmed by their teacher-centred teaching. When participants were asked to explain what they understood CLT was, participants responded as follows:

- Participant Red: 'Okay. That we should teach first so that they will be able to communicate themselves well. Ah, talking of languages and also, ah, for them to be able to read and understand what is in their books and be able to answer some questions properly.'

- Participant Pink: 'Ah, it is how you pass on knowledge to the learners. The words that you use you have to be, ah, usually careful in terms of their level so that they will be able to get what you will be saying.'

- Participant Purple: 'My understanding about Communicative Language Teaching is whereby, ah, children are given the opportunity to express themselves. They are given the chance to find out things for themselves. They are given more time to explore different things and they are given the opportunity to do things on their own rather than being lectured to like what was done long ago.'

- Participant White: 'Alright. Ah, as a teacher, living in Zimbabwe and teaching, ah, English, ah, languages and second language to our children, ah, is all about, ah, teaching the skills that involve reading, ah, listening, speaking skills and writing skills.'

- Participant Green: 'Umm. Communicative Language Teaching I think it all deals with teacher interacting with the child, ah, when teaching language.' 
We appreciated that participants White and Purple both viewed CLT as an approach that would assist learners to be communicatively competent in English. However, participants Green and Pink's views suggested the traditional approach, as they believed that the language teacher should be concerned with the learners' understanding of the content of the lesson and passing knowledge to the learners. They were concerned with the teacher's interaction with the learners, but did not consider that interaction among the learners was even more important. Participants Pink and Green's responses show a limited understanding of the principles of CLT. However, we found that participant Purple, who showed some understanding of CLT, could have derived the idea from the word 'communicative'. Given the limited understanding of CLT by most of the participants, we determined that the participants did not use interactive activities due to a lack of understanding what they should do in a CLT classroom as well as a dearth of staff development in the form of workshops and conferences on how to implement CLT.

We noted that the teachers' knowledge was determined by the training that they had received, as this influenced their beliefs. When asked about the teaching methods that they were taught at the teachers' training college, the participants gave the following responses:

- Participant White: 'I think our training was inadequate. It was not adequate at all. Because then we were the pioneer group of ZINTEC training our group was an experimenting group because they working with, our college was just, ah, you know, what can I say government was using just one group per year. So, they had to find another group. So, we were just being an experimental group. So, it wasn't all that effective.'

- Participant Purple: 'Oh yes the other difficulties that we may have are, that, I think we still need some workshops, ah, on CLT.'

The findings showed that the participants lacked adequate training in CLT, which was supported by participants White and Purple's comments in the following excerpts:

- Participant White: 'It was difficult to get adequate training. We had a shortage of resources such as modules. Sometimes we would not find lecturers to assist us. Most of the times we looked for our own resources and during that time we were computer illiterate to google and get information. So, I recommend the government may in-service us to improve the skills we have.'

- Participant Purple: 'Oh, we do have a lot of challenges that you may have are, ah, I think we still need some staff development, on how to use the CLT approach.'

We also found that the participants' lack of training was evident in their presentation of lessons and in their choice of activities. We assumed that, due to a lack of training, the teachers used the traditional approaches, which they themselves had been taught by their own teachers. The way in which they presented their lessons indicated that they believed that if the traditional approaches worked then, they could still work today. These beliefs led to ineffective implementation of CLT. The findings showed that participants White and Purple emphasised the need for in-service training of qualified teachers to sharpen and improve their teaching skills. We established that participants' head teachers did not orchestrate any staff development conferences or meetings to enhance teachers' knowledge on CLT. The Handbook of the scheme of association (Department of Teacher Education, 2012) holds the assumption that qualified teachers are well equipped in teaching all the subjects offered at primary school level. However, participants indicated that they lacked knowledge of CLT and 
requested us to provide them with handouts to assist them with implementing CLT. Participants White and Purple responded as follows:

- Participant White: 'I think we need handouts to understand Communicative Language Teaching.'

- Participant Purple: 'I know it is a good approach but I do not understand it.'

From the observed lessons we deduced that, while participants knew the importance of CLT, they could not implement it properly since they had little knowledge of the teaching approach. This influenced their pedagogical beliefs and as a result, participants taught in the way that they were taught by their own teachers, using traditional approaches. It emerged that there was a need for in-service training to equip teachers regarding how to effectively implement CLT.

The teachers' pedagogical beliefs about the CLT approach clearly showed the factors that affected how the teachers implemented CLT. It was evident that the participants had not been exposed to adequate theoretical guidance on the CLT approach, a variable that influenced their knowledge, understanding, and choice of learning aids. From the responses that the participants gave, it was clear that the teachers had not yet benefited from staff development programmes to help them transform their beliefs and change roles from being transmitters of knowledge to facilitators of communication.

In addition, it was evident that participants and learners also acted as human mediation tools, which is a principle of CLT. During pair and group work, participants moved around assisting learners, while learners were encouraged to assist their peers. What this meant was that participants provided their learners with scaffolds while learners provided their peers with scaffolds to assist them to reach their zone of proximal development. We argue that, although scaffolding was a requirement, and was indeed provided, participants did not display the necessary skills for effective communicative learning to take place. We attribute this to the fact that participants needed in-service training to transform their beliefs so that they could effectively implement the CLT approach. The lack of training can be attributed to the fact that the majority of teachers did not major in English. Therefore, it was apparent to us that participants, as mediators of learning, did not possess the linguistic skills required to teach communicatively due to a lack of adequate training. This resulted in CLT not being effectively implemented.

\section{CONCLUSION}

The intention of this article was to account for teachers' beliefs and how these affect the implementation of CLT. The research revealed that teachers' methodological and pedagogical beliefs influenced the way in which they implemented CLT. The research also revealed that teachers' pedagogical beliefs sometimes differed from the way in which they implemented CLT. This was evidenced by teachers acknowledging the importance of pair and group work, which are tenets of CLT, although they did not have the capacity to apply the activities in practice. Most lessons where characterised by traditional methods of teaching, which were teacher centred. This made it difficult for learners to achieve communicative competence as they merely answered questions. The teachers' methodological beliefs influenced them to teach grammar through rote learning and memorisation. 
We argue that the effective implementation of CLT is dependent upon the choices of activities that teachers prefer to use (methodological beliefs) as well as the knowledge they have about CLT (pedagogical beliefs). These teachers' beliefs impact on their classroom practices and contribute to the ineffective implementation of CLT. We purport that inadequate knowledge on CLT and inadequate training on handling a CLT classroom have contributed to the beliefs held by teachers. We recommend that teacher training colleges equip student teachers with both methodological and pedagogical skills, which may enable them to effectively implement the CLT approach in lessons. If these skills are emphasised both practically and theoretically in colleges, it may assist teachers to have hands-on experience of how to manage CLT lessons. Head teachers in schools should also continuously present staff-development workshops. If such staff-development actions are coupled with practical classroom demonstrations on how to implement CLT, it may assist teachers in the implementation thereof, and may also assist in changing their beliefs about the approach.

\section{REFERENCES}

AHMAD, S \& C RAO. 2013. Applying communicative approach in teaching English as a foreign language: a case study of Pakistan. Porta Linguarum, 20:187-293.

ALUWIHARE-SAMARANAYAKE, D. 2012. Ethics in qualitative research: A view of the participants' and researchers' world from a critical standpoint. International Journal of Qualitative Methods, 11(2):64-81.

AL-ZAHRANI, MY \& A AL-BARGI. 2017. The impact of teacher questioning on creating interaction in EFL: A discourse analysis. English Language Teaching, 10(6):135.

ASL, ES. 2015. Comparative study of grammar-translation method (GTM) and communicative language teaching (CLT) in language teaching methodology. Human Journals, 1(3):16-25.

BROWN, HD. 2001. Teaching by principles: An interactive approach to language pedagogy. White Plains, NY: Pearson.

BROWN, HD. 2007. Principles of language learning and teaching (5th ed.). San Francisco, CA: Pearson.

BROWN, HD. 2014. Principles of language learning and teaching. New York: Pearson.

BROWN, P \& S GASKINS. 2014. Language acquisition and language socialization. In Cambridge handbook of linguistic anthropology. London: Cambridge University Press. 187-226.

BURKE, A. 2011. Group work: How to use groups effectively. Journal of Effective Teaching, 11(2):87-95.

CROSS, R. 2010. Language teaching as socio-cultural activity: Rethinking language teacher practice. The Modern Language Journal, 94(3):434-452.

DENZIN, NK \& YS LINCOLN. 2005. The SAGE handbook of qualitative research. Thousand Oaks, CA: Sage.

DEPARTMENT OF TEACHER EDUCATION. 2012. Handbook of the scheme of association. Harare: University of Zimbabwe Press.

DRAKE, JR. 2012. A critical analysis of active learning and an alternative pedagogical framework for introductory information systems courses. Journal of Information Technology Education, 11, 39-52.

ENGESTRÖM, Y. 2014. Learning by expanding. London: Cambridge University Press.

ENGESTRÖM, Y. 1987. Learning by expanding: an activity-theoretical approach to developmental research. Helsinki: Orienta-Konsultit. Available from http://communication.ucsd.edu/MCA/Paper/Engestrom/expanding [Accessed: 2 November 2018].

FATEMEH, M \& R HAMIDREZA. 2012. Experiential education contributing to language learning. International Journal of Humanities and Social Science, 2(21):268-277. 
GINSBURG, M. 2009. Active-learning pedagogies as a reform initiative: Synthesis of case studies. Washington, DC: Academy for Educational Development.

HIEP, HP. 2007. Communicative language teaching: unity within diversity. ELT Journal, 61(3):193201.

KADENGE, M \& D NKOMO. 2011. Language policy, translation and language development in Zimbabwe. Southern African Linguistics and Applied Language Studies, 29(3):259-274.

KAISER, K. 2009. Protecting respondent confidentiality in qualitative research. Qualitative Health Research, 19(11):1632-1641.

KANYONGO, GY. 2005. Zimbabwe's public education system reforms: Successes and challenges. International Education Journal, 6(1):65-74.

KIM, M. 2014. A comparison of pedagogical practices and beliefs in international and domestic mathematics teaching assistants. Journal of International Students, 4(1):74-88.

KOLB, DA. 1984. Experiential learning: Experience as the source of learning and development. Englewood Cliffs, NJ: Prentice Hall.

LITTLEWOOD, W. 2013. Developing a context-sensitive pedagogy for communication oriented language teaching. English Teaching, 68(3):3-25.

LITTLEWOOD, W. 2014. Communication-oriented language teaching: Where are we now? Where do we go from here? Language Teaching, 47(3):349-362.

LUNA SCOTT, C. 2015. The futures of learning 3: What kind of pedagogies for the 21st century? S.1.: United Nations Educational Scientific and Cultural Organisation.

MAREE, JG. 2007. First steps in research. Pretoria: Van Schaik.

MINISTRY OF EDUCATION, SPORT \& CULTURE. 2006. Director's circular minute no. 36. Guidelines on work coverage in primary and secondary schools. Harare: Ministry of Education, Sport, and Culture.

MINISTRY OF EDUCATION, SPORT \& CULTURE. 1986. Primary school English syllabus Grade 1-7. Harare: Curriculum Development Unit.

MUTEKWA, A. 2013. The challenges of using the communicative approach (CA) in the teaching of English as a second language (ESL) in Zimbabwe: implications for ESL teacher education. Africa Education Review, 10(3):539-553. https://doi.org/10.1080/18146627.2013.853547

NISHINO, T. 2012. Modelling teacher beliefs and practices in context: A multimethods approach. The Modern Language Journal, 96(3):380-399.

NIU, R \& S ANDREWS. 2012. Commonalities and discrepancies in L2 teachers' beliefs and practices about vocabulary pedagogy: A small culture perspective. TESOL Journal, 6:134-154.

NOWELL, LS, JM NORRIS, DE WHITE \& NJ MOULES. 2017. Thematic analysis: Striving to meet the trustworthiness criteria. International Journal of Qualitative Methods, 16(1):1-13.

NZIRAMASANGA, C. 1999. Report of the presidential commission of enquiry into Zimbabwe education and training. Harare: Government of Zimbabwe Printers.

OUNIS, A \& T OUNIS. 2017. Tunisian secondary EFL school teachers' perceptions regarding communicative language teaching: An exploratory survey. International Journal of Humanities and Cultural Studies, 4(1):188-208.

PARVIN, S. 2016. The implementation of communicative language teaching (CLT) method for improving speaking skill in Bangladeshi language classroom at secondary and higher secondary level. Research Journal of English Language and Literature, 4(1):2395-2636.

PRETORIUS, EJ. 2012. Butterfly effects in reading? The relationship between decoding and comprehension in Grade 6 high poverty schools. South African Association for Language Teaching, 46(2):74-95.

PRETORIUS, EJ. 2014. Supporting transition or playing catch-up in Grade 4? Implications for standards in education and training. Perspectives in Education, 32(1):51-76.

RAHMAN, MM, MKM SINGH \& A PANDIAN. 2018. Exploring ESL teacher beliefs and classroom practices of CLT: A case study. International Journal of Instruction, 11(1):295-310.

RICHARDS, JC. 2006. Communicative language teaching today. Cambridge: Cambridge University Press.

RICHARDS, JC \& TS RODGERS. 2001. Approaches and methods in language teaching (2nd ed.). Cambridge: Cambridge University Press. 
SARI, R. 2014. The use of communicative language teaching (CLT) approach to teach speaking recount text to eight grade students of SMPN 2 Jombang. RETAIN, 2(2):208-217.

SEKIZIYIVU, S \& CB MUGIMU. 2017. Communicative language teaching strategies for German as a foreign language in Uganda. Journal of Language Teaching and Research, 8(1):8-15.

SURI, H. 2011. Purposeful sampling in qualitative research synthesis. Qualitative research journal, 11(2):63-75.

TAEBI, I, TORABI, Z \& MA FARSANI. 2016. Depicting EFL learners' and teachers' perceptions toward communicative language teaching: Voices from Iran. The Iranian EFL Journal, 12(4):28.

VYGOTSKY, LS. 1978. Interaction between learning and development. In M Cole, V John-Steiner, S Scriber \& E Souberman (Eds), Mind and society: The development of higher psychological processes. Cambridge, MA: Harvard University Press.

WERTSCH, JV. 1985. Vygotsky and the social formation of mind. Cambridge, MA: Harvard University Press.

XIANGUI, Z. 2005. Learning theories and second language learning. Celia Journal, 28(5):120-127.

$\mathrm{XU}$, L. 2012. The role of teachers' beliefs in the language teaching-learning process. Theory \& Practice in Language Studies, 2(7).

\section{BIOGRAPHICAL NOTES}

Dr Mildred Shingirirai Nyamayedenga holds a $\mathrm{PhD}$ in Curriculum and Instructional Design and Development. She is a senior lecturer in Communication Skills in the faculty of Social \& Gender Transformative Sciences at Women's University in Africa. Her research interests are in English language learning and teaching, multilingualism and the effects of the first language in second language learning. She is interested in how teachers of English handle their classroom practice. Email: mildrednyamayedenga@gmail.com

Dr Lizette de Jager is a Fulbright scholar and TAU Fellow. She holds a PhD in Curriculum and Instructional Design and Development with a focus on Sociolinguistics. She teaches English literature and language and English methodology in the Department of Humanities Education, Faculty of Education at the University of Pretoria. She is the Teaching and Learning Coordinator for the Department. Her research interests, supervision, and publications are in the field of English education, applied linguistics, pragmatics, instructional design, translanguaging and pedagogy. She is a keen supporter of technology integration in the classroom and currently leads a research team on integrating apps for language teaching. Email: lizette.dejager@up.ac.za 